\title{
Time-space analysis to evaluate cell-based quality of service in bus rapid transit station platforms through passenger-specific area
}

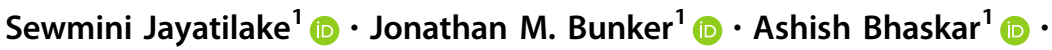 \\ Marc Miska ${ }^{1}$
}

Accepted: 20 January 2021 / Published online: 9 March 2021

(C) The Author(s), under exclusive licence to Springer-Verlag GmbH, DE part of Springer Nature 2021

\begin{abstract}
It is important to evaluate the quality of service (QoS) of bus rapid transit (BRT) station platform operation. Passenger-specific area (PSA) is used as a QoS measure which is determined by considering passenger activities separately. As passengers perform various activities on the same platform space, there is a need to evaluate BRT platform QoS by considering the activities collectively. When evaluating transit station platforms, many researchers calculated PSA for the whole platform area, while very few researchers highlighted the importance of evaluating the platform as small, partitioned areas. By considering these findings and gaps in the literature, this study evaluates QoS of the platform on a cell by cell basis using PSA. We use time-space analysis and passenger-minutes of each activity to develop a methodology to determine PSA, by considering stationary passengers, circulating passengers, and passengers overall. To evaluate platform QoS, we define threshold service levels using passenger-minutes of activities and Fruin's QoS criteria. For the case study BRT station, we find that PSA varies significantly between platform cells. It is evident from the results that it is important to identify highly congested areas in the platform and apply measures to improve platform QoS.
\end{abstract}

Sewmini Jayatilake

sewmini.arachchillage@hdr.qut.edu.au

Jonathan M. Bunker

j.bunker@qut.edu.au

Ashish Bhaskar

ashish.bhaskar@qut.edu.au

Marc Miska

marc.miska@qut.edu.au

1 Queensland University of Technology, School of Civil and Environmental Engineering, Brisbane, QLD 4001, Australia 
Keywords Bus rapid transit - Station platforms - Platform cell · Time-space analysis · Passenger-specific area $\cdot$ Quality of service $\cdot$ Service levels

JEL classification R15 econometric and input-output models · Other models

\section{Introduction}

The station platform is the most important passenger interface on a bus rapid transit (BRT) system, as it connects passengers with the BRT system (Hinebaugh 2009). Operation of a BRT station platform is complex and directly impacts transit system performance. The major operational processes on a platform involve various passenger activities, bus operation, and interaction between passengers and buses. From the time when passengers enter the platform until they board, or from the time when passengers alight from a bus until they exit the platform, they perform several activities in time and space, while they are stationary or while they are circulating. Therefore, platforms should possess sufficient space to provide for stationary and circulating activities (Kittelson and Assoc 2013). As all passenger activities interact, it is necessary to evaluate the whole platform as a system in order to quantify and qualify its operation, and where appropriate, to provide improvement options.

It is important to evaluate the quality of service (QoS) of BRT station platform operation. Measures of QoS relate to passengers' perception regarding the availability, and comfort and convenience of the transit service offered (Islam et al. 2016; Kittelson and Assoc 2013). Insufficient space on a platform can cause passenger inconvenience and discomfort. To measure the QoS of spatial comfort, we define the area available per passenger $\left(\mathrm{m}^{2} / \mathrm{p}\right)$ on a transit platform or portion thereof as passenger-specific area (PSA) (Jayatilake et al. 2020). PSA varies due to the available platform area, number of passengers, and the activities they perform on the station platform or a portion thereof.

Even when sufficient space is available across the whole platform, passengers may not spread evenly, resulting in a variation in this QoS of spatial comfort. Some areas of the platform may be subject to more congestion while others may rarely be subject to usage by passengers (Kittelson and Assoc 2013). This occurs due to the variation in space required by passengers when performing various activities on the platform (Kittelson and Assoc 2013). Therefore, the combination of passenger activities that occur on the platform and space occupied by passengers during each activity warrants thorough consideration. Methods defined in the literature are mainly confined to be used for one type of passenger activity, so they are not applicable to areas that involve multiple passenger activities. BRT station platforms are facilities that allow passengers to perform various activities on common platform space (Kittelson and Assoc 2013). Therefore, this study is focused on developing a methodology to quantify and qualify the operation of a BRT station platform by considering the various passenger activities together, but by 
compartmentalizing the platform into cells that each contain relatively homogeneous conditions. We apply the methodology to a testbed BRT station platform to investigate the variation of PSA from cell to cell. To evaluate QoS of spatial comfort with the use of measured PSA, we adapt thresholds defined by Fruin (1992) across the platform cells.

Public transport and station platform operation have been impacted by the very recent onset of COVID-19. Voß et al. (2020) have highlighted the need for higher capacities at bus stations during pandemic situations when social distancing measures are in place. The effect of the pandemic situation on the BRT station platform operation has been researched by the authors (Jayatilake and Bunker 2021), but is not considered under the scope of the research outlined herein.

The aim of this study is to understand the complex system of BRT station platform operation and to combine the physical and operational characteristics of a BRT platform with the various passenger activities, in order to determine PSA on a cell-by-cell basis and across the whole platform, and to evaluate QoS of spatial comfort. Section 2 of this article reviews current literature to understand the existing theories and to identify the gaps in the literature. Section 3 creates a conceptual model of BRT platform operation. Referenced to this model, in Sect. 4, we combine system characteristics and the various passenger activities using timespace (TS) analysis to develop a methodology to determine PSA on a cell-by-cell basis and across the whole platform. Section 5 discusses the assignment of utility weights to estimate PSA while Sects. 6 and 7 present the use of collected data to train and test the model. Section 8 presents the results of the model with training and testing data. Sections 9 and 10 summarise the discussion and conclusion, respectively.

\section{Literature review}

Numerous studies have considered the platform operation of transit systems. Most have studied operational improvements to provide better performance. The Transit Capacity and Quality of Service Manual suggests that pedestrian microscopic simulation software is the best method to analyse platform operation (Kittelson and Assoc 2013). Many researchers (Duduta and Subedi 2015; Lee et al. 2001) have used various software platforms for microscopic pedestrian simulation of transit stations, focusing on particular sections or characteristics of the transit station platform rather than looking at the total platform area. However, considerable time and effort is required to use pedestrian microscopic simulation software to model a platform, and the user must be educated about the theoretical constructions and assumptions behind the software. According to Bunker (2018), when using microscopic simulation software to study the capacity and QoS of BRT systems, it is not easy to control every parameter in the simulation model. Therefore, the need remains for a deterministic model that can be used to analyse the complex operation of transit platforms.

Transit station design is highly correlated to running way segregation (Hinebaugh 2009). Bus stations range from simple stops, enhanced stops, designated stations, to 
intermodal terminals. These different types of stations vary primarily with characteristics that are related to platform layout, station access, platform height, and vehicle passing capability (Hinebaugh 2009). Differences in these characteristics can influence platform operation. BRT stations consist of side platforms or centre platforms (Kittelson and Assoc 2013). A typical BRT station has a linear platform with several off-line loading areas. Under this layout and with relatively high volumes of buses, passengers are uncertain about the loading area where their bus would stop (Jaiswal et al. 2010), unlike a railway station where only one train occupies the platform at a time, such that passengers have the ability to board through any train door.

When considering BRT platform operation with different station designs, Wiggenraad (2001) identified how access locations affect platform crowding. Research by Duduta and Subedi (2015) considered a BRT station in Latin America, which has a median station with off-board fare collection at turnstiles. They found that the level of crowding at the station is affected by station dimensions and the number and type of turnstiles. Voß et al. (2020) have indicated that different bus station designs influence different postures of waiting passengers. The BRT system in Brisbane, Australia was studied by Jaiswal (2010). Fare collection occurs onboard with no turnstile areas or fare pedestals on platforms. Its dedicated station characteristics include linear off-line loading areas, side platforms with overtaking lanes, on-board fare collection, front door boarding and many other passenger amenities at the station (Jaiswal 2010). The wide variation in BRT station characteristics highlights the need to consider different layouts and characteristics when applying methodologies to evaluate platform operation.

In order to develop a model of platform operation, it is necessary to understand the various passenger activities and their interaction. According to Teng et al. (2020), major passenger activities on a station are walking and queuing. When considering BRT station platforms, existing models focused towards a particular passenger activity such as waiting (Fan and Machemehl 2002) and the dwelling process (Fletcher and El-Geneidy 2013; Jaiswal et al. 2008; Li et al. 2012), without focusing on the whole platform operation. However, passenger activities occur simultaneously and stochastically at BRT station platforms and cannot be easily separated in space as they change with time (Bosina et al. 2015). Therefore, it is essential to develop a methodology to evaluate BRT platform operation by considering the various passenger activities together.

When evaluating transit station platforms, many researchers analysed the platform as a whole, while few researchers (Hänseler et al. 2016; Seriani et al. 2017; $\mathrm{Wu}$ and Ma 2013) considered the partitioning of the platform into discrete areas. In Hänseler et al. (2016), the circulating space was partitioned into a set of areas to calculate PSA. Seriani et al. (2017) identified highly congested sections of the platform area that involve boarding and alighting passenger interactions. In $\mathrm{Wu}$ and Ma (2013), the waiting areas in the platform were identified and the service level of the waiting areas evaluated separately. They highlighted the importance of dividing the platform into areas for evaluation, without evaluating the platform as a whole. However, these studies were carried out in relation to rail transit stations rather than BRT stations. Also, they did not consider the partitioning of waiting and circulating 
areas into small cells. No means of evaluation of QoS of spatial comfort by partitioning BRT station platforms into cells has been identified in the literature.

For the deterministic modelling of platform operation to evaluate performance, Fruin (1992) used analytical methods employing service levels, which form the thresholds across the typical A to F scale used to appraise spatial comfort QoS. In relation to transit stations, different service level criteria were developed by considering the average pedestrian space, personal comfort, the degree of internal mobility, the number of passengers waiting, and their waiting times (Fruin 1971, 1992; Hridya and Geeva 2018; Yang et al. 2015). However, the service level thresholds defined by Fruin (1992) are widely accepted and used (Duduta and Subedi 2015; Hänseler et al. 2016; Hermant and De Gersigny 2010). As the service level thresholds that were defined as a function of PSA are useful to evaluate circulating and stationary areas, many researchers have used PSA as the main indicator to evaluate transit station performance (Duduta and Subedi 2015; Lam et al. 1999). It is a widely used measure to evaluate passengers' perceived comfort and facility performance (Hänseler et al. 2016).

Fruin's service level thresholds (Fruin 1992) were defined for walking and queuing passenger activities separately and therefore can be applied to determine QoS of areas with uniform passenger activity. As various activities occur on a BRT platform, it is not accurate to use just one of these two service level thresholds to evaluate QoS of a platform area. Further, the service level thresholds defined by Fruin (1992) are most applicable to small spaces as they qualify the overall density of the space. Therefore, highly congested areas on a transit station platform may not be able to be identified readily (Evans and Wener 2007). In the absence of combined service level thresholds that can be used to evaluate the whole platform area, development of service level thresholds for transit platform areas where circulating and waiting activities occur, would be useful for more accurate evaluation of spatial comfort QoS.

The Transit Capacity and Quality of Service Manual suggests the use of TS analysis (Kittelson and Assoc 2013). This analysis form combines PSA ( $\left.\mathrm{m}^{2} / \mathrm{p}\right)$ to achieve service level thresholds and factors them according to the passenger-time spent on each activity within the given space. Application of TS analysis to transit platforms is important as it considers that circulating and stationary passengers occupy different spaces over different time periods, whereas in discrete QoS criteria, time variation of different activities is not considered (Benz 1986; Grigoriadou and Braaksma 1986). Although the TS analysis procedure and its general application for rail transit stations is stated the Transit Capacity and Quality of Service Manual (Kittelson and Assoc 2013), we have not discovered its application to evaluate BRT station platforms in terms of PSA in the literature.

On transit platforms, a passenger's selection of waiting location and circulation route are influenced by several factors. When quantitatively analysing the route choice behaviour of passengers, Muraleetharan and Hagiwara (2007) developed a multinomial logit model. Using the model, the probability of selecting an alternative from a set of alternatives was found according to utility functions created for each alternative (Miskeen et al. 2013). In the creation of utility functions for pedestrian route choice, most researchers focused on minimising the travel time or travel 
distance. However, according to the model created by Muraleetharan and Hagiwara (2007), passengers choose their route not only by considering the shortest distance, but also by considering the overall QoS. This highlights the importance of evaluating PSA and service level thresholds for QoS at station platforms. Therefore, in platform operation evaluation, we consider that multinomial logit modelling for passenger waiting location selection and route selection is a suitable choice.

Based on the gaps in the literature, there is a need to develop a deterministic methodology to evaluate spatial comfort QoS on a BRT platform, by combining stationary and circulation activities together and determining PSA on a cell-by-cell basis and across the whole platform.

\section{Conceptual model of BRT platform operation}

We observed the operation of a case BRT platform, which is detailed in Sect. 4. The major activities that are undertaken by passengers include circulating, waiting, queuing, alighting, and boarding. We define the activity of circulating to include walking and moving with aids including, but not limited to, wheelchairs and pushers. While performing these activities, passengers undertake other incidental actions, such as looking for the information provided on the displayed bus timetables and real-time bus arrival information screen (Jaiswal 2010), utilizing smart card and food vending machines (Elhamshary et al. 2016), use of mobile phones, chatting with fellow passengers, and use of help phones for disability assistance. This study focuses on the major passenger activities that are performed on the platform (irrespective of the interaction with buses). Figure 1 categorises them into circulating activities and stationary activities. Activities performed by passengers entering onto the platform include; circulating from the entrance to a waiting location, waiting for the desired bus, circulating from the waiting location to the loading area where the desired bus is stopped to dwell, queuing to board, and boarding. Similarly, activities performed by passengers exiting the platform include alighting from their bus and circulating to the platform exit. Interchanging passengers and their activities were not considered at this stage of the study, however they will be considered during the following stages.

Between different passengers, these activities may occur at different locations on the platform, so it can be difficult to isolate particular activities to particular locations. Therefore, we first considered factors affecting passenger activities on a

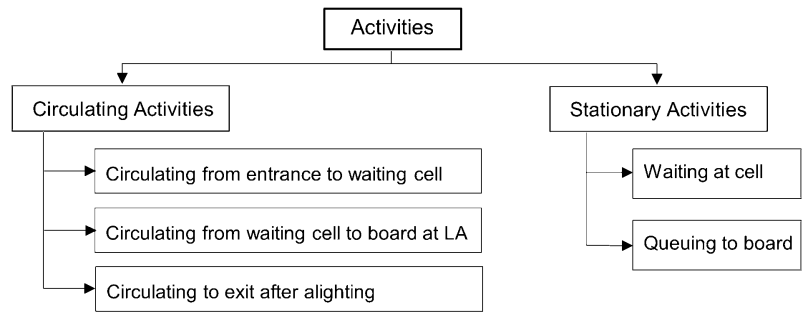

Fig. 1 Classification of passenger activities on the BRT platform (Jayatilake et al. 2020) 
BRT platform, and their interconnection, by reviewing the Transit Capacity and Quality of Service Manual (Kittelson and Assoc 2013).

Figure 2 illustrates our model to analyse BRT station platform operation. In this model, we combine factors related to passenger activities on the platform to produce stationary PSA and circulating PSA within each cell and across the whole platform. This process considers all major passenger activities that take place on a common platform space, rather than limiting the process to an area with a particular

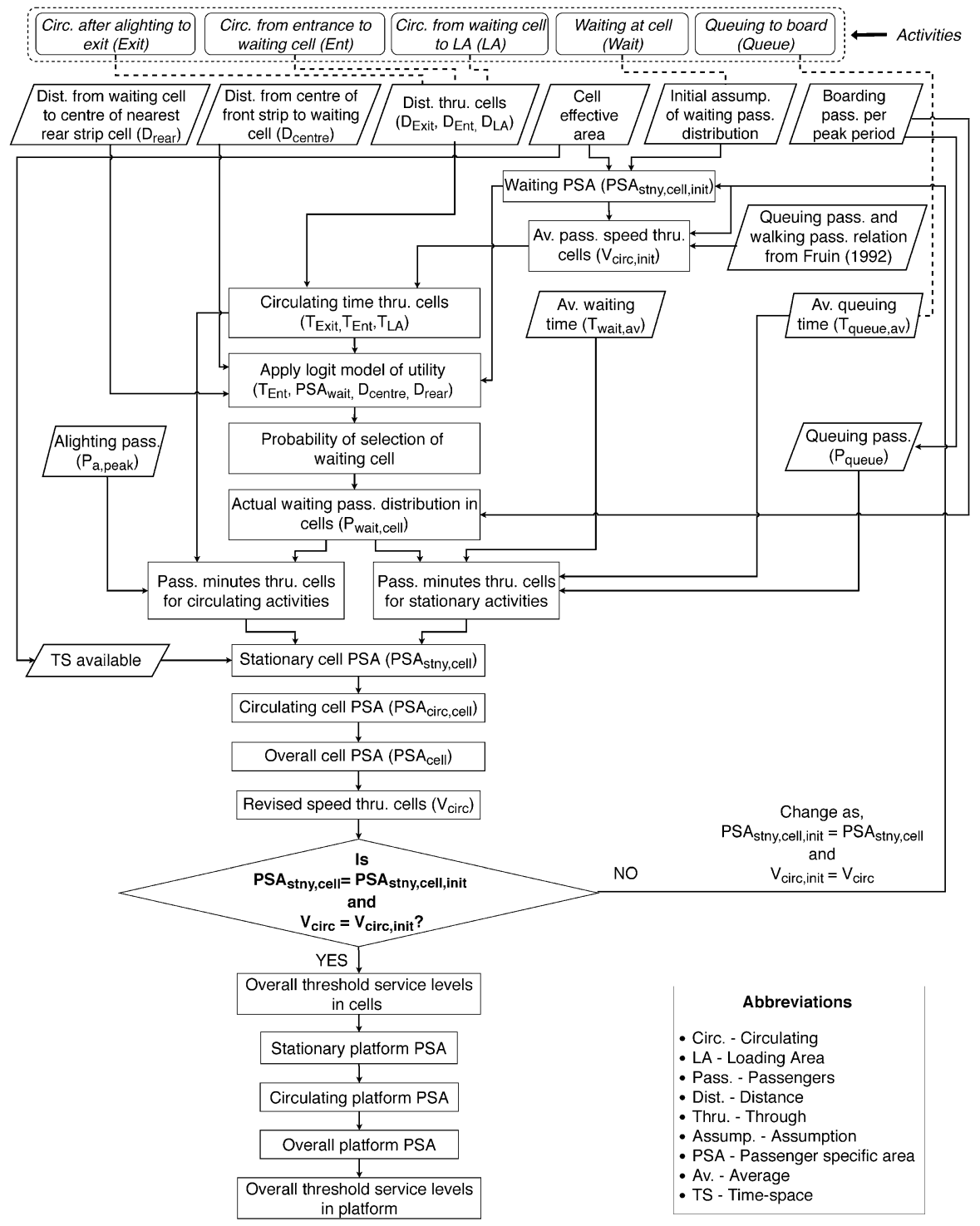

Fig. 2 Model to analyse BRT station platform operation 
passenger activity. Finally, stationary PSA and circulating PSA are combined to obtain overall PSA within each cell and across the whole platform. The concepts behind this model are explained in the next section.

\section{Methodology}

\subsection{Case study station}

This research analyses BRT platform operation using the South East Busway in Brisbane, Australia as the case study. To identify the study station platform, preliminary manual observation of the platform operation was carried out at several BRT stations along the corridor. Considering the restricted geometry, a high number of timetabled services observing the platform, and the platform crowd observed during the peak period, we selected the outbound platform at Mater Hill Busway station as the case study station. This is the fourth station on the South East Busway and is $2.65 \mathrm{~km}$ in the outbound direction from the Central Business District core station of King George Square.

The study station platform has three loading areas. To account for a variation in PSA across a BRT platform, we divided the platform area into 12 cells before applying the model as shown in Fig. 3. The reasons for this division are that buses typically have two doors yielding 6 door positions along the platform edge, passengers tend to use the back half of the platform (cells 7-12) predominantly for waiting, and use the front half (cells 1-6) for a combination of accessing buses and waiting. The primary station entrance/exit is fully accessible, and is located at the upstream end of the platform, adjacent to cells 6 and 12. A secondary entrance/exit is located at the downstream end of the platform, adjacent to cells 1 and 7; however, this entrance/exit is a tall staircase that is rarely used, so we excluded it from the model.

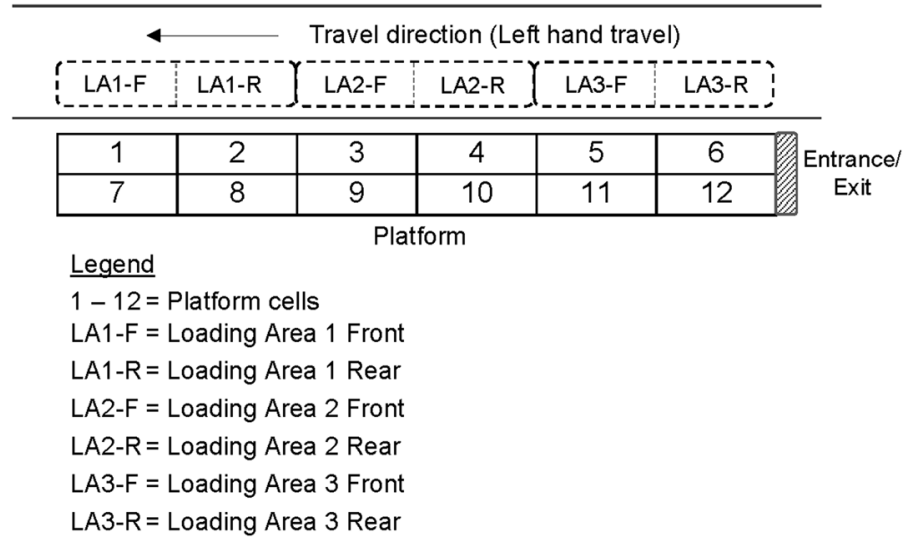

Fig. 3 Study BRT platform and loading area configuration (Jayatilake et al. 2020) 
Table 1 Notations used in the article

\begin{tabular}{ll}
\hline Notation & Explanation \\
\hline$A$ & Scalar \\
{$[A]_{i \times j}$} & Matrix; where $\mathrm{i}=$ number of rows, $\mathrm{j}=$ number of columns \\
{$[A] \times[B]$} & Matrix multiplication \\
{$[A] \varnothing[B]$} & Element-wise matrix division (Hadamard division) \\
{$[A] \circ[B]$} & Element-wise matrix multiplication (Hadamard product) \\
{$[J]_{i \times j}$} & Matrix of ones; where i = number of rows, $\mathrm{j}=$ number of columns \\
{$[A]^{T}$} & Transpose of a matrix \\
$\ln [A]$ & Element-wise natural logarithm of a matrix \\
$\exp [A]$ & Element-wise natural exponential of a matrix \\
$\Sigma[A]$ & Summation of all elements of a matrix (scalar) \\
Mean $[A]$ & Arithmetic mean of all elements of a matrix (scalar) \\
\hline
\end{tabular}

The model is based upon matrix algebra, so lends itself to the development of a spreadsheet. The notations used in this paper are described in Table 1. Along with matrix algebra, utility functions were used to determine proportions of passengers performing activities in cells. The model was trained and tested using the quantitative data collected at the study platform. During model training, optimum values for the utility weights were identified.

Table 2 Input details for the evaluation of outbound platform, mater Hill Busway station

\begin{tabular}{|c|c|c|}
\hline Item & Value & Units \\
\hline Peak of the peak duration & 15 & $\min$ \\
\hline Evaluation period & \multicolumn{2}{|c|}{$\begin{array}{l}\text { Evening peak of the } \\
\text { peak period }(3.30 \mathrm{pm}- \\
3.45 \mathrm{pm})\end{array}$} \\
\hline Platform length & $\begin{array}{l}45.0 \\
(147.7)\end{array}$ & $\mathrm{m}(\mathrm{ft})$ \\
\hline $\begin{array}{l}\text { Net platform width (excluding edge width in front of yellow safety line and } \\
\text { obstructions) }\end{array}$ & $\begin{array}{l}3.75 \\
(12.3)\end{array}$ & $\mathrm{m}(\mathrm{ft})$ \\
\hline \multicolumn{3}{|c|}{ Number of buses servicing at each loading area during the evaluation period (Different bus routes) } \\
\hline Loading area 1 & 14 & \multirow{3}{*}{$\begin{array}{r}\text { Bus/peak } \\
15 \text { min }\end{array}$} \\
\hline Loading area 2 & 15 & \\
\hline Loading area 3 & 12 & \\
\hline $\begin{array}{l}\text { Average number of boarding passengers per bus (Without interchanging } \\
\text { passengers) }\end{array}$ & 7.35 & $\mathrm{P}_{\mathrm{b}} / \mathrm{bus}$ \\
\hline Average number of alighting passengers per bus & 1.13 & $\mathrm{P}_{\mathrm{a}} /$ bus \\
\hline
\end{tabular}




\subsection{Testbed station and inputs}

This stage of the study relied upon data collected through manual observation of platform operation. Table 2 provides the input parameters and input data collected at the study BRT station. Data was collected during the evening 15-min peak of the peak period of a mid-weekday (Tuesday). This study was conducted before the COVD-19 situation. Changed passenger behaviour and BRT platform operation during the COVID-19 pandemic period is evaluated through further research (Jayatilake and Bunker 2021).

We selected the analysis period as 15-min peak of the peak duration (Kittelson and Assoc 2013). The number of buses servicing at each loading area (regardless of the route number), and the number of boarding and alighting passengers per bus during this period, was identified through the collected data.

Depending upon crowding levels and activities that passengers perform, the area occupied by passengers may vary between cells. According to Fruin (1992), when compared with the space required for stationary passengers, walking (circulating) passengers require additional lateral and longitudinal space for body sway, walking spacing and space to avoid contact with others. The following method was developed to calculate PSA in each cell by the performed activity.

\subsection{Initial estimation of passenger circulating speeds}

We use a TS analysis to calculate the time and space occupied by passengers as they engage in different activities in a cell. When the effective area of each cell is known, the available TS in each cell may be determined according to Eq. 1 (Kittelson and Assoc 2013). Equations 1 and 2 show abbreviated matrices denoted by square parentheses of 1 row $\times 12$ columns as denoted by the subscript, where each position represents a corresponding cell position on the platform.

$$
\left[\text { TS }_{\text {avail }}\right]_{1 \times 12}=d u r_{p k} \times\left[A_{\text {cell }, e f f}\right]_{1 \times 12}
$$

where $T S_{\text {avail }}=$ available TS in cell $\left(\mathrm{m}^{2} \cdot \mathrm{min}\right) ; d u r_{p k}=$ peak of the peak duration $(\min ) . A_{\text {cell }, \text { eff }}=$ effective area of cell $\left(\mathrm{m}^{2}\right)$.

The speed of passengers on a BRT platform may vary with passenger density. Therefore, first we use the expected number of waiting passengers in platform cells at a given time, taken as averages from manually collected data, to estimate the stationary reference PSA in each cell according to Eq. 2.

$$
\left[P S A_{\text {stny,cell,init }}\right]_{1 \times 12}=\left[A_{\text {cell }, \text { eff }}\right]_{1 \times 12} \varnothing\left[P_{\text {wait }, \text { init }}\right]_{1 \times 12}
$$

where, $P S A_{\text {stny,cell,init }}=$ estimation of stationary reference PSA $\left(\mathrm{m}^{2} / \mathrm{p}\right)$ in cells based upon a cell-by-cell distribution of waiting passengers. $P_{\text {wait }, \text { init }}=$ cell-by-cell distribution of expected number of waiting passengers (p) at a given time, during the peak of the peak period. 
We then apply the relationship between circulating speed and circulating PSA according to Fruin (1971) to determine the average of passenger circulating speeds through each cell. While we use Fruin's values in relation to "walking", future stages of our research will consider circulation using aids such as wheelchair and pusher. The relationship between circulating PSA and stationary PSA, based upon Fruin (1992) values, is provided in Eq. 3, which we use to determine the equivalent stationary PSA $\left(P S A_{e q v, s t n y}\right)$ in Eq. 4.

We use the relationship between pedestrian space $\left(\mathrm{m}^{2} / \mathrm{p}\right)$ and walking speed $(\mathrm{m} /$ min) that is exhibited in the Transit Capacity and Quality of Service Manual (Kittelson and Assoc 2013) and Fruin (1992) to chart the variation in $P S A_{\text {eqv,stny }}$ with circulating speed $\left(V_{c i r c, F r}\right)(\mathrm{m} / \mathrm{min})$. This is necessary to obtain the relationship of Eq. 5, which yields circulating speed as a function of $P S A_{\text {eqv }, \text { stny }}$. Pedestrians space, average speed and service level standards defined by Fruin (Fruin 1971, 1992) for walkways and queuing areas are applicable to transit platforms, as they act as storage areas for waiting/queuing passengers and as a movement space for circulating passengers (Fruin 1992; Kittelson and Assoc 2013).

$$
\begin{gathered}
R_{s / c}=\frac{P S A_{\text {stny }, F r, i}}{P S A_{\text {circ }, F r, i}}=0.384 \\
P S A_{\text {eqv }, \text { stny }}=0.384 \times P S A_{\text {circ }, F r} \\
V_{\text {circ }, F r}=21.42 \times \ln \left(P S A_{\text {eqv }, \text { stny }}\right)+78.17
\end{gathered}
$$

where, $R_{s / c}=$ Ratio between stationary (queuing) PSA and circulating (walking) PSA in Fruin (1992). $P S A_{\text {stny }, F r, i}=$ Stationary (Queuing) reference PSA $\left(\mathrm{m}^{2} / \mathrm{p}\right)$ for service level $i$ in Fruin (1992), $i \in(A, B, C, D, E, F) . P S A_{c i r c, F r, i}=$ Circulating (Walking) reference PSA $\left(\mathrm{m}^{2} / \mathrm{p}\right)$ for service level $i$ in Fruin (1992), $i \in(A, B, C, D, E, F)$.

We estimate the average initial speed while circulating through each cell as a function of the initial estimation of waiting PSA in each cell, according to Eq. 6. The maximum passenger speed is set to $82 \mathrm{~m} / \mathrm{min}$, considering the relationship between pedestrian space $\left(\mathrm{m}^{2} / \mathrm{p}\right)$ and walking speed $(\mathrm{m} / \mathrm{min})$ exhibited in Transit Capacity and Quality of Service Manual (Kittelson and Assoc 2013) and Fruin (1992). Isotropy of walking speed is assumed within each cell (Hänseler et al. 2016).

$$
\left[V_{\text {circ,init }}\right]_{1 \times 12}=\operatorname{Min}\left(\left(21.42 \times \ln \left[P S A_{\text {stny,cell,init }}\right]_{1 \times 12}+78.17 \times[J]_{1 \times 12}\right), 82\right)
$$

where, $V_{\text {circ, } \text {,init }}=$ Average initial passenger speed $(\mathrm{m} / \mathrm{min})$ while circulating through cells.

\subsection{Passenger routes}

To estimate the times taken by passengers to perform circulating activities, their travel distances and travel speeds are required. The distances taken by passengers during each activity are not easy to determine directly. Therefore, to estimate average circulating distances, we estimate passenger routes for each activity as 
shown in Fig. 4. We apply similar patterns to all cells to calculate passenger average circulating distances to/from the centres of cells. The platform has one common entrance and exit location at the upstream end of the platform (right side of Fig. 3).

Having estimated distances for the routes taken for each activity according to Fig. 4, we then estimate passenger circulation times using speeds through cells. The optimisation process that we carry out after the calculation of PSA in cells (as shown in Fig. 2) is detailed in the next section, along with the estimation of distances and circulation times of passengers for circulating activities.

\subsection{Circulating activities}

We define the average circulating time through each cell of the platform, when circulating from each starting location to each destination, as 'cell-wise average time'. We define the total circulating time from each starting location to each

1. Routes followed when circulating from entrance to waiting cell

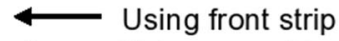

---- Using rear strip
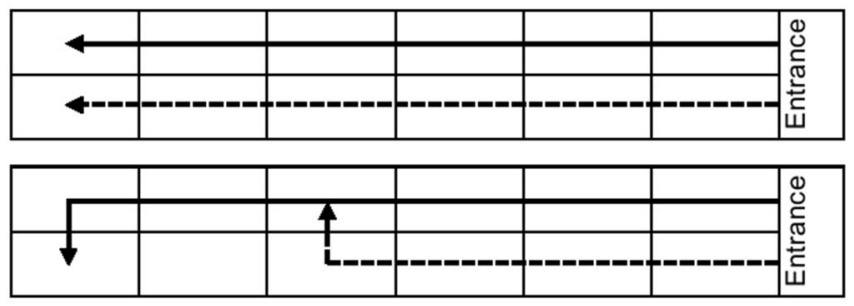

2. Routes followed when circulating from waiting cell to board

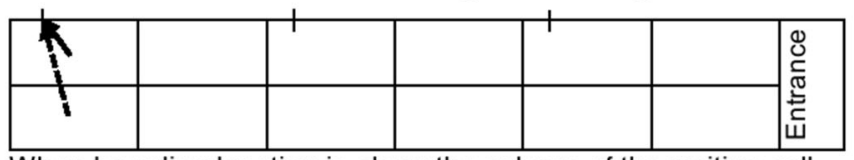

When boarding location is along the column of the waiting cell

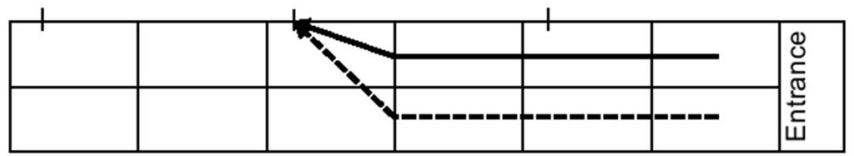

When boarding location is not along the column of the waiting cell

3. When circulating to exit after alighting

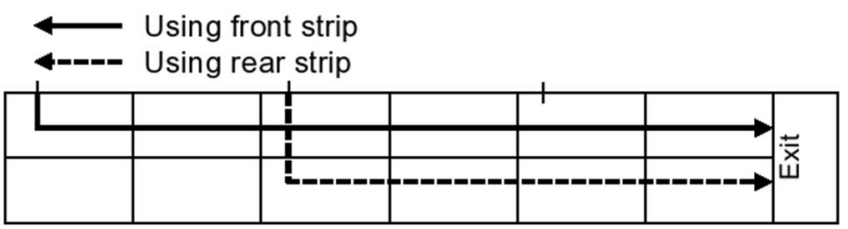

Fig. 4 Example passenger routes from/to cells on BRT platform (Jayatilake et al. 2020) 
destination as 'total average time'. This is determined by summing values from the cell-wise average time.

\subsubsection{Circulating from entrance to waiting cell}

Passengers who circulate from the platform entrance to their waiting cell may select either the front strip or rear strip. The distance through each cell when circulating to each waiting cell using either the front or rear strip may be calculated by using passenger routes defined in Fig. 4. This yields a 12 rows $\times 12$ columns matrix, where the rows represent the 12 cells of the platform through which the passengers circulate, and the columns represent the destination cell number. A separate matrix is created for each, the front strip and the rear strip. With these two matrices, and the matrix of average speed while circulating through each cell, the matrices of circulating time (min) through each cell, for each strip, are estimated according to Eq. 7. $\left[V_{\text {circ }}\right]_{1 \times 12}$ is taken from the previous iteration of the optimisation routine, or in the initial iteration is set to $\left[V_{\text {circ,init }}\right]_{1 \times 12}$.

$$
\left[T_{\text {str,circ }, \text { ent }}\right]_{12 \times 12}=\left[D_{\text {str,circ }, e n t}\right]_{12 \times 12} \varnothing\left[V_{\text {circ }}\right]_{12 \times 1}^{T}
$$

where, $D_{\text {str }, \text { circ }, \text { ent }}=$ Circulating distance through a cell $(\mathrm{m})$ when circulating using the strip to waiting cell, str $\in$ (front, rear). $T_{\text {str,circ,ent }}=$ Circulating time through a cell (min) when circulating using the strip to the waiting cell, str $\in$ (front, rear). $V_{\text {circ }}=$ Average passenger speed $(\mathrm{m} / \mathrm{min})$ while circulating through a cell.

To determine the average circulating time from the platform entrance to each cell, matrices that result from Eq. 7 for each of the front and rear strips are combined using a logit model of utility. For each cell, the proportion of passengers who use a strip to circulate from the platform entrance to that cell in order to wait is estimated according to Eqs. 8 to 10 .

$$
\begin{aligned}
& {\left[u_{\text {str,circ,ent }}\right]_{1 \times 12}=[J]_{1 \times 12} \varnothing\left([J]_{1 \times 12} \times\left[T_{\text {str,circ,ent }}\right]_{12 \times 12}\right)} \\
& {\left[\text { Lgt }_{\text {str,circ }, \text { ent }}\right]_{1 \times 12}=\exp \left[u_{\text {str,circ,ent }}\right]_{1 \times 12}} \\
& {\left[p_{\text {str }, \text { irc }, \text { ent }}\right]_{1 \times 12}=\left[L g t_{\text {str,circ }, \text { ent }}\right]_{1 \times 12} \varnothing\left(\left[\operatorname{Lg} t_{\text {frnt }, \text { circ }, \text { ent }}\right]_{1 \times 12}+\left[L g t_{\text {rear }, \text { irr }, \text { ent }}\right]_{1 \times 12}\right)}
\end{aligned}
$$

where, $u_{\text {str,circ,ent }}=$ Utility for circulating time from platform entrance to the waiting cell using strip,str $\in$ (front, rear). $L g t_{\text {str, circ,ent }}=$ Logit model of circulating time from platform entrance to the waiting cell using strip, str $\in$ (front, rear $)$. $p_{\text {str,circ,ent }}$ $=$ Proportion of passengers circulating from the platform entrance to the waiting cell using strip, str $\in$ (front, rear).

We then weight the times taken using the front and rear strips. Equation 11 estimates the cell-wise average time $\left(T_{a v, \text { cell,circ,ent }}\right)(\mathrm{min})$, while Eq. 12 estimates the total average time $\left(T_{a v, \text { tot,circ,ent }}\right)(\mathrm{min})$ when circulating from the platform entrance to each waiting cell. Equation 12 yields a row matrix with 12 elements, where each element corresponds to the platform cell. 


$$
\begin{aligned}
& \begin{aligned}
{\left[T_{\text {av }, \text { cell }, \text { circ }, \text { ent }}\right]_{12 \times 12}=} & {\left[T_{\text {frnt }, \text { irc }, \text { ent }}\right]_{12 \times 12} \circ\left[p_{\text {frnt }, \text { circ }, \text { ent }}\right]_{1 \times 12}+\left[T_{\text {rear }, \text { circ }, \text { ent }}\right]_{12 \times 12} } \\
& \circ\left[p_{\text {rear }, \text { circ }, \text { ent }}\right]_{1 \times 12}
\end{aligned} \\
& {\left[T_{a v, \text { tot,circ,ent }}\right]_{1 \times 12}=[J]_{1 \times 12} \times\left[T_{\text {av,cell,circ,ent }}\right]_{12 \times 12}}
\end{aligned}
$$

\subsubsection{Circulating from a waiting cell to board}

For passengers circulating from a waiting cell to board, we estimate the circulating distance through each cell using the passenger routes shown in Fig. 4. This yields a separate matrix for each loading area, representing the distance through each cell when circulating from each waiting cell to the boarding location of each loading area. We use these matrices, with the matrix of average speed while circulating through each cell, to estimate the circulating time through each cell according to Eq. 13, where each column represents the waiting cell number and the rows indicate the 12 cells of the platform.

$$
\left[T_{\text {circ }, L A l}\right]_{12 \times 12}=\left[D_{\text {circ }, L A l}\right]_{12 \times 12} \varnothing\left[V_{\text {circ }}\right]_{12 \times 1}^{T}
$$

where, $T_{\text {circ }, L A l}=$ Circulating time through a cell $(\mathrm{min})$ when circulating from the waiting cell to the loading area $l, l \in(1,2,3) . D_{\text {circ }, L A l}=$ Circulating distance through cell $(\mathrm{m})$ when circulating from the waiting cell to the loading area $l$, $l \in(1,2,3)$.

To combine the three resulting matrices of the three loading areas, we estimate the boarding passenger distribution at each loading area. For the peak of the peak condition, we estimate the number of passengers boarding at each loading area using Eq. 14, and the boarding passenger distribution at each loading area using Eq. 15, from data collected.

$$
\begin{gathered}
P_{b, L A l}=P_{b, b u s} \times B_{L A l} \\
D_{P b, L A l}=\frac{P_{b, L A l}}{\sum_{l=1}^{3} P_{b, L A l}} \times 100 \%
\end{gathered}
$$

where, $P_{b, L A l}=$ Number of passengers $(\mathrm{p})$ boarding at loading area $l$ during the peak of the peak period, $l \in(1,2,3)$. $P_{b, b u s}=$ Number of boarding passengers $(\mathrm{p})$ per bus. $B_{L A l}=$ Number of buses stopping to serve passengers at loading area $l$ during the peak of the peak period, $l \in(1,2,3) . D_{P b, L A l}=$ Boarding passenger distribution at loading area $l, l \in(1,2,3)$.

We use these values, along with the matrices from Eq. 13, to estimate the cellwise average time ( $\mathrm{min}$ ) when circulating from each waiting cell to any loading area $\left(T_{a v, \text { cell,circ }, L A}\right)$, according to Eq. 16. We use Eq. 17 to estimate the total average time (min) when circulating from each waiting cell to any loading area $\left(T_{a v, t o t, c i r c, L A}\right)$. 


$$
\begin{gathered}
{\left[T_{a v, \text { cell }, \text { circ }, L A}\right]_{12 \times 12}=\sum_{l=1}^{3}\left(D_{P b, L A l} \times\left[T_{\text {circ }, L A l}\right]_{12 \times 12}\right)} \\
{\left[T_{a v, t o t, \text { circ }, L A}\right]_{1 \times 12}=[J]_{1 \times 12} \times\left[T_{a v, \text { cell }, \text { circ }, L A}\right]_{12 \times 12}}
\end{gathered}
$$

\subsubsection{Alighting and circulating to exit}

A matrix of distance when circulating through each cell from alighting to the platform exit, for each of the front and rear strips, is estimated using the passenger routes defined in Fig. 4. For each strip, this matrix and the matrix of average speed while circulating through each cell are used to estimate the time taken by alighting passengers to circulate to the exit. Each matrix is indicated by a 12 rows $\times 6$ columns matrix, where the 12 rows indicate the 12 cells of the platform and the 6 columns indicate the alighting locations (front 6 cells of the platform). Equation 18 provides the matrices of circulating time through each cell when circulating to exit using a strip (front or rear).

$$
\left[T_{\text {str,circ,exit }}\right]_{12 \times 6}=\left[D_{\text {str,circ,exit }}\right]_{12 \times 6} \varnothing\left[V_{\text {circ }}\right]_{12 \times 1}^{T}
$$

where, $T_{\text {str,circ,exit }}=$ Circulating time through cell $(\mathrm{min})$ when circulating to platform exit using strip, str $\in($ front, rear $)$. $D_{\text {str,circ,exit }}=$ Circulating distance through cell (m) when circulating to platform exit using strip, str $\in$ (front, rear).

To determine the average circulating time from the alighting location to the exit, the proportions of passengers using each of the front and rear strips are estimated respectively according to their utility. Equations 19 to 21 indicate the calculations for a strip.

$$
\begin{gathered}
{\left[u_{\text {str,circ,exit }}\right]_{1 \times 6}=[J]_{1 \times 6} \varnothing\left([J]_{1 \times 12} \times\left[T_{\text {str,circ,exit }}\right]_{12 \times 6}\right)} \\
{\left[L g t_{\text {str,circ,exit }}\right]_{1 \times 6}=\exp \left[u_{s t r, \text { circ }, e x i t}\right]_{1 \times 6}} \\
{\left[p_{\text {str,circ,exit }}\right]_{1 \times 6}=\left[L g t_{\text {str,circ,exit }}\right]_{1 \times 6} \varnothing\left(\left[L g t_{\text {frnt }, \text { circ,exit }}\right]_{1 \times 6}+\left[L g t_{\text {rear,circ,exit }}\right]_{1 \times 6}\right)}
\end{gathered}
$$

where, $u_{\text {str,circ,exit }}=$ Utility for circulating time from alighting to exit using strip $s t r \in($ front, rear $)$. Lgt $_{\text {str,circ,exit }}=$ Logit model of circulating time from alighting to exit using strip str $\in($ front, rear $) . p_{\text {str,circ,exit }}=$ Proportion using strip $s t r \in$ (front, rear) to circulate from alighting to exit.

These proportions are combined with resulting matrices from Eq. 18, to find the cell-wise average time when circulating from alighting cells to the platform exit $\left(T_{a v, \text { cell,circ,exit }}\right)$, as shown in Eq. 22.

$$
\begin{aligned}
{\left[T_{\text {av }, \text { cell,circ }, \text { exit }}\right]_{12 \times 6}=} & {\left[T_{\text {frnt }, \text { circ }, \text { exit }}\right]_{12 \times 6} \circ\left[p_{\text {frnt,circ }, \text { exit }}\right]_{1 \times 6}+\left[T_{\text {rear,circ }, \text { exit }}\right]_{12 \times 6} } \\
& \circ\left[p_{\text {rear }, \text { circ }, \text { exit }}\right]_{1 \times 6}
\end{aligned}
$$


Similar to the circulating times, it is necessary to find the time taken to perform stationary activities. Prior to this, estimation of actual waiting passenger distribution through cells is required as discussed in the next section.

\subsection{Utility estimation and probability of selection of waiting cell}

Each cell on the platform is considered as a location within which passengers may select to wait. We use utility functions for the factors that we consider affect how passengers select their waiting cell. These factors include; circulating distance from entrance to waiting cell (Jaiswal et al. 2008), waiting PSA in each cell (Krstanoski 2014), distance from centre of front strip to waiting cell (considering ease of access to any of the loading areas and availability of real-time bus arrival information screen at centre of front strip), and direct distance from the centre of the waiting cell to the centre of the nearest rear strip cell (considering the availability of platform amenities including seating and smart card vending machines at the rear strip of the platform, and the extent to which waiting passengers avoid interaction with boarding and alighting passengers). We estimate the probability of selecting each cell to wait using the following method. All matrices in this section are row matrices with 12 columns, where each position in the matrix indicates the respective cell position of the platform.

\subsubsection{Utility of circulating distance from entrance to waiting cell}

To determine the average circulating distance from the platform entrance to each cell, the distances from front and rear strips are combined using a logit model of utility. Considering the distance from entrance to each cell, the proportion of passengers who use a strip, either front or rear, to circulate is estimated according to Eqs. 23 to 25 .

$$
\begin{gathered}
{\left[u_{\text {str,dist }, \text { ent }}\right]_{1 \times 12}=[J]_{1 \times 12} \varnothing\left([J]_{1 \times 12} \times\left[D_{\text {str,circ,ent }}\right]_{12 \times 12}\right)} \\
{\left[L g t_{\text {str,dist,ent }}\right]_{1 \times 12}=\exp \left[u_{\text {str,dist }, \text { ent }}\right]_{1 \times 12}} \\
{\left[p_{\text {str,dist }, \text { ent }}\right]_{1 \times 12}=\left[\text { Lgt } t_{\text {str,dist }, \text { ent }}\right]_{1 \times 12} \varnothing\left(\left[\text { Lgt } t_{\text {frnt,dist }, \text { ent }}\right]_{1 \times 12}+\left[\text { Lgt } t_{\text {rear,dist }, \text { ent }}\right]_{1 \times 12}\right)}
\end{gathered}
$$

where $u_{\text {str,dist }, \text { ent }}=$ utility of the circulating distance from the platform entrance to the waiting cell using strip str $\in$ (front, rear). Lgt $_{\text {str,dist }, \text { ent }}=$ logit model of circulating the distance from the platform entrance to the waiting cell using strip $s t r \in($ front, rear $) . p_{\text {str }, \text { dist }, \text { ent }}=$ proportion of passengers using the strip, considering the circulating distance from the platform entrance to the waiting cell str $\in$ (front, rear).

Equations 26 and 27 estimate the cell-wise average circulating distance $\left(D_{a v, c e l l, c i r c, e n t}\right)(\mathrm{m})$ and total average circulating distance $\left(D_{a v, \text { tot,circ,ent }}\right)(\mathrm{m})$ from 
the platform entrance to each waiting cell, by combining the use of each of the front and rear strips, respectively.

$$
\begin{aligned}
& {\left[D_{\text {av }, \text { cell }, \text { circ }, \text { ent }}\right]_{12 \times 12}=\left[D_{\text {frnt }, \text { circ }, \text { ent }}\right]_{12 \times 12} \circ\left[p_{\text {frnt }, \text { dist }, \text { ent }}\right]_{1 \times 12}+\left[D_{\text {rear }, \text { circ }, \text { ent }}\right]_{12 \times 12}} \\
& \circ\left[p_{\text {rear, dist, ent }}\right]_{1 \times 12} \\
& {\left[D_{a v, \text { tot }, \text { circ }, \text { ent }}\right]_{1 \times 12}=[J]_{1 \times 12} \times\left[D_{\text {av,cell,circ,ent }}\right]_{12 \times 12}}
\end{aligned}
$$

We then estimate the utility of circulating distance from the entrance to waiting cell $\left(U_{\text {Dist }, \text { ent }}\right)$ according to Eq. 28.

$$
\left[U_{\text {Dist }, \text { ent }}\right]_{1 \times 12}=[J]_{1 \times 12}-\frac{\left[D_{a v, \text { tot }, \text { irr }, \text { ent }}\right]_{1 \times 12}}{\operatorname{Mean}\left[D_{a v, \text { tot }, \text { circ }, \text { ent }}\right]_{1 \times 12}}
$$

\subsubsection{Utility of waiting passenger-specific area in cell}

We estimate the utility of waiting PSA in each cell using Eq. 29, where $\left[P S A_{\text {stny,cell }}\right]_{1 \times 12}$ is taken from the previous iteration of the optimisation routine, or in the initial iteration is set to the matrix of $\left[P S A_{\text {stny,cell,init }}\right]_{1 \times 12}$.

$$
\left[U_{\text {wait }, P S A}\right]_{1 \times 12}=\frac{\left[P S A_{\text {stny }, \text { cell }}\right]_{1 \times 12}}{\text { Mean }\left[P S A_{\text {stny }, \text { cell }}\right]_{1 \times 12}}-[J]_{1 \times 12}
$$

where, $U_{\text {wait }, P S A}=$ utility of a waiting passenger-specific area in a cell. $P S A_{\text {stny, cell }}=$ stationary reference PSA in a cell $\left(\mathrm{m}^{2} / \mathrm{p}\right)$.

\subsubsection{Utility of distance from centre of front strip to waiting cell}

With the availability of real-time bus arrival information screens at the centre of the front strip of the platform, and the availability of three linear loading areas where buses stop on a first-come-first-served basis, passengers may select their waiting cell close to the platform centre. Therefore, we estimate the utility of distance from the centre of the front strip to each waiting cell using Eq. 30.

$$
\left[U_{\text {Dist }, \text { cntr }}\right]_{1 \times 12}=[J]_{1 \times 12}-\frac{\left[D_{\text {front }, \text { cntr }}\right]_{1 \times 12}}{\text { Mean }\left[D_{\text {front }, \text { cntr }}\right]_{1 \times 12}}
$$

where, $U_{\text {Dist,cntr }}=$ Utility of the distance from the centre of the front strip to the waiting cell. $D_{\text {front }, \text { cntr }}=$ Distance from the centre of the front strip to the waiting cell (m). 


\subsubsection{Utility of the distance from the centre of a waiting cell to the centre of the nearest rear strip cell}

We estimate the utility of distance from the centre of each waiting cell to the centre of the nearest rear strip cell, using Eq. 31. This factor accounts for the availability of platform amenities at the rear strip of the platform (including seating, bus arrival timetable information, and smart card vending machines) and the extent to which waiting passengers avoiding interaction with the bus dwelling process that takes place along the front strip.

$$
\left[U_{\text {Dist }, \text { rear }}\right]_{1 \times 12}=[J]_{1 \times 12}-\frac{\left[D_{\text {Rear }, \text { cell }}\right]_{1 \times 12}}{\text { Mean }\left[D_{\text {Rear }, \text { cell }}\right]_{1 \times 12}}
$$

where $U_{\text {Dist,rear }}=$ Utility of the distance from the centre of the waiting cell to the centre of the nearest rear strip cell. $D_{\text {Rear,cell }}=$ Distance from the centre of the waiting cell to the centre of the nearest rear strip cell (m).

\subsubsection{Overall cell utility and probability of waiting at a cell}

We assign a weight to each factor's utility, before combining them to estimate the overall cell utility. Section 5 discusses the assignment of utility weights in this study.

By combining each utility with the weight assigned, we estimate the overall cell utility $\left[U_{\text {oall }}\right]_{1 \times 12}$ according to Eq. 32 . We then estimate the probability of a passenger choosing a cell to wait $\left[p_{\text {oall }}\right]_{1 \times 12}$ using Eqs. 33 and 34 .

$$
\begin{gathered}
{\left[U_{\text {oall }}\right]_{1 \times 12}=W_{\text {Dist }, \text { ent }} \times\left[U_{\text {Dist }, \text { ent }}\right]_{1 \times 12}+W_{\text {wait }, \text { } P A} \times\left[U_{\text {wait }, P S A}\right]_{1 \times 12}+W_{\text {Dist }, \text { cntr }}} \\
\times\left[U_{\text {Dist }, \text { cntr }}\right]_{1 \times 12}+W_{\text {Dist }, \text { rear }} \times\left[U_{\text {Dist }, \text { rear }}\right]_{1 \times 12} \\
{\left[\text { Lgt } t_{\text {oall }}\right]_{1 \times 12}=\exp \left[U_{\text {oall }}\right]_{1 \times 12}} \\
{\left[p_{\text {oall }}\right]_{1 \times 12}=\frac{\left[\text { Lgt } t_{\text {oall }}\right]_{1 \times 12}}{\sum\left[\text { Lgt } t_{\text {oall }}\right]_{1 \times 12}}}
\end{gathered}
$$

where, $W_{\text {Dist }, \text { ent }}=$ utility weight of factor for distance from entrance to waiting cell. $W_{\text {wait }, P S A}=$ utility weight of factor for waiting PSA in a cell. $W_{\text {Dist }, \text { cntr }}=$ utility weight of the factor for the distance from the centre of the front strip to the waiting cell. $W_{\text {Dist }, \text { rear }}=$ utility weight of the factor for the distance from the centre of the waiting cell to the centre of the nearest rear strip cell. $L g t_{\text {oall }}=$ logit model of overall cell utility.

The resulting probability matrices can be used to estimate the number of waiting passengers in each cell during the peak period, as described in the next section. 


\subsection{Stationary activities}

\subsubsection{Waiting and queuing passengers in each cell}

When considering the activity of waiting, we distribute the total number of boarding passengers per peak of the peak period (p) across all three loading areas, amongst the cells according to the probability values estimated from Eq. 34, using Eq. 35.

$$
\left[P_{\text {wait }, \text { cell }}\right]_{1 \times 12}=\left(\sum_{l=1}^{3} P_{b, L A l}\right) \times\left[p_{\text {oall }}\right]_{1 \times 12}
$$

where, $P_{\text {wait }, \text { cell }}=$ total waiting passenger distribution in a platform cell during the peak of the peak period (p).

Next, we use Eq. 36 to determine the expected number of waiting passengers in the cells at a given instant in time.

$$
\left[P_{\text {wait }, \text { cell }, \text { ins }}\right]_{1 \times 12}=\left[P_{\text {wait }, \text { cell }}\right]_{1 \times 12} \times T_{\text {wait }, a v} \div d u r_{p k}
$$

where, $P_{\text {wait,cell,ins }}=$ expected number of waiting passengers in a cell at a given instant in time (p). $T_{\text {wait }, a v}=$ average passenger waiting time (min).

The calculation of the average passenger waiting time is described in the next section.

When considering the activity of queuing, we apply boarding passenger percentages at each loading area to determine the expected number of queuing passengers in each cell using Eq. 37. We assume that boarding passengers may queue in cells 1, 3 and 5 only, as this BRT system allows only front door boarding and each loading area occupies the length of two cells.

$$
\begin{aligned}
{\left[P_{\text {quеие }}\right]_{1 \times 12}=} & {\left[\begin{array}{llllllllllll}
D_{P b, L A 1} & 0 & D_{P b, L A 2} & 0 & D_{P b, L A 3} & 0 & 0 & 0 & 0 & 0 & 0 & 0
\end{array}\right] } \\
& \times \sum_{l=1}^{3} P_{b, L A l}
\end{aligned}
$$

where, $P_{\text {queue }}=$ Number of queuing passengers in cell during the peak of the peak period (p).

\subsubsection{Waiting and queuing passenger times in each cell}

In addition to the expected number of passengers in the cells, the time taken by each passenger to perform each activity is required. Average passenger waiting time is determined from the data collected over the 15-min peak of the peak period. Average passenger queuing time is determined by taking the summation of the bus door opening time, the alighting duration, and the average boarding duration. We assume bus door opening time to equal $2.0 \mathrm{~s}$ based on the observations made, and use values of average boarding and alighting time per passenger from individual 
passenger service times given in the Transit Capacity and Quality of Service Manual (Kittelson and Assoc 2013).

- Average passenger waiting time, $T_{\text {wait }, a v}=4.25$ minutes across the platform (from data collected)

- Average passenger queuing time, $T_{\text {queue }, a v}=0.178$ minutes

Knowing the expected number of passengers in the cells and time taken for each activity, we then combine these values to determine the passenger-minutes taken by each activity, as is discussed in the next section.

\subsection{Passenger-minutes in each cell}

To determine the passenger-minutes in a cell, we consider each activity separately. We use Eqs. 38 to 42 to estimate passenger-minutes for the activities of waiting, queuing, circulating from the entrance to the waiting cell, circulating from the waiting cell to the loading area, and circulating to the exit after alighting, respectively. Each equation results in a row matrix with 12 elements that represent respective cells of the platform.

\subsubsection{Waiting}

$$
\left[P M_{\text {wait }}\right]_{1 \times 12}=\left[P_{\text {wait }, \text { cell }}\right]_{1 \times 12} \times T_{\text {wait }, \text { av }}
$$

where $P M_{\text {wait }}=$ passenger-minutes in a cell for waiting (p.min).

\subsubsection{Queuing}

$$
\left[P M_{\text {queиe }}\right]_{1 \times 12}=\left[P_{\text {queиe }}\right]_{1 \times 12} \times\left(T_{\text {queue }, \text { av }}\right)
$$

where $P M_{\text {queue }}=$ passenger-minutes in a cell for queuing (p.min).

\subsubsection{Circulating from entrance to waiting cell}

$$
\left[P M_{\text {circ }, \text { ent }}\right]_{1 \times 12}=\left(\left(\left[P_{\text {wait }, \text { cell }}\right]_{1 \times 12} \circ\left[T_{\text {av,cell,circ,ent }}\right]_{12 \times 12}\right) \times[J]_{12 \times 1}\right)^{T}{ }_{1 \times 12}
$$

where, $P M_{\text {circ,ent }}=$ passenger-minutes in a cell for circulating from the entrance to the waiting cell (p.min).

\subsubsection{Circulating from the waiting cell to board}

$$
\left[P M_{\text {circ }, L A}\right]_{1 \times 12}=\left(\left(\left[P_{\text {wait }, \text { cell }}\right]_{1 \times 12} \circ\left[T_{\text {av,cell,circ }, L A}\right]_{12 \times 12}\right) \times[J]_{12 \times 1}\right)_{1 \times 12}^{T}
$$

where $P M_{\text {circ }, L A}=$ passenger-minutes in a cell for circulating from the waiting cell to the loading area (p.min).

\subsubsection{Alighting and circulating to the exit}

$$
\left[P M_{\text {circ }, \text { exit }}\right]_{1 \times 12}=\left(\left(\left[P_{a}\right]_{1 \times 6} \circ\left[T_{\text {av,cell,circ,exit }}\right]_{12 \times 6}\right) \times[J]_{6 \times 1}\right)_{1 \times 12}^{T}
$$

where $P M_{\text {circ,exit }}=$ passenger-minutes in a cell for circulating to the platform exit 
after alighting (p.min). $P_{a}=$ number of passengers alighting onto a cell during the peak of the peak period (p).

Because passengers alight onto the front six cells of the platform, $P_{a}$ is indicated by a row matrix with 6 elements. To estimate this matrix, we consider the number of buses stopping at each loading area $\left(B_{L A l}\right)$, the expected number of alighting passengers per bus $\left(P_{a, b u s}\right)$, and alighting proportions by door channel as provided in the Transit Capacity and Quality of Service Manual (Kittelson and Assoc 2013).

Using the passenger-minutes calculated for each activity, we determine the total passenger-minutes taken for stationary activities $\left(P M_{\text {stny }}\right)$ and for circulating activities $\left(P M_{\text {circ }}\right)$ according to Eqs. 43 and 44, respectively.

$$
\begin{gathered}
{\left[P M_{\text {stny }}\right]_{1 \times 12}=\left[P M_{\text {wait }}\right]_{1 \times 12}+\left[P M_{\text {queue }}\right]_{1 \times 12}} \\
{\left[P M_{\text {circ }}\right]_{1 \times 12}=\left[P M_{\text {circ }, \text { ent }}\right]_{1 \times 12}+\left[P M_{\text {circ }, L A}\right]_{1 \times 12}+\left[P M_{\text {circ }, \text { exit }}\right]_{1 \times 12}}
\end{gathered}
$$

Using these equations, we estimate BRT platform PSA using the following procedure.

\subsection{BRT platform passenger-specific area}

We re-estimate stationary reference PSA $\left(\mathrm{m}^{2} / \mathrm{p}\right)$ in each cell $\left(P S A_{\text {stny,cell }}\right)$ using Eq. 45 in the next iteration of the optimisation routine. This represents the notional value when overall passenger-specific area in a cell is represented as a stationary PSA equivalent.

$$
\left[P S A_{\text {stny }, \text { cell }}\right]_{1 \times 12}=\left[T S_{\text {avail }}\right]_{1 \times 12} \varnothing\left(\left[P M_{\text {stny }}\right]_{1 \times 12}+\frac{\left[P M_{\text {circ }}\right]_{1 \times 12}}{0.384}\right)
$$

We use Eq. 46 to estimate circulating reference PSA $\left(\mathrm{m}^{2} / \mathrm{p}\right)$ in each cell $\left(P S A_{\text {circ,cell }}\right)$. This represents the notional value when overall passenger-specific area in a cell is represented as a circulating PSA equivalent.

$$
\left[P S A_{\text {circ }, \text { cell }}\right]_{1 \times 12}=\frac{\left[P S A_{\text {stny }, \text { cell }}\right]_{1 \times 12}}{0.384}
$$

Both equations yield row matrices with 12 elements representing the 12 cells of the platform. Following settlement of the optimisation routine, the result calculated using Eq. 45 or 46 may be compared with Fruin's service level thresholds (Fruin 1992) for stationary or circulating areas, respectively.

Given that the cells on the BRT platform accommodate both stationary and circulating activities, we can provide more clarity by calculating the overall PSA $\left(\mathrm{m}^{2} / \mathrm{p}\right)$ in a cell as the weighted average of $P S A_{\text {stny, cell }}$ and $P S A_{\text {circ,cell }}$ using Eq. 47, where $P M_{\text {stny }}$ and $P M_{\text {circ }}$ are used as weights. This overall PSA reflects all passengers together irrespective of their activities, because additional lateral and longitudinal space is required by circulating passengers than stationary passengers. 


$$
\begin{aligned}
{\left[P S A_{\text {cell }}\right]_{1 \times 12}=} & \left(\left[P S A_{\text {stny,cell }}\right]_{1 \times 12} \circ\left[P M_{\text {strny }}\right]_{1 \times 12}+\left[P S A_{\text {circ,cell }}\right]_{1 \times 12}\right. \\
& \left.\circ\left[P M_{\text {circ }}\right]_{1 \times 12}\right) \varnothing\left(\left[P M_{\text {stny }}\right]_{1 \times 12}+\left[P M_{\text {circ }}\right]_{1 \times 12}\right)
\end{aligned}
$$

where $P S A_{\text {cell }}=$ overall PSA in a cell $\left(\mathrm{m}^{2} / \mathrm{p}\right)$.

Next, for use in the next iteration of the optimisation routine, using Eq. 48 we reestimate the average passenger circulating speed through each cell according to Fruin (1971). The maximum passenger speed is set to $82 \mathrm{~m} / \mathrm{min}$, considering the relationship between pedestrian space $\left(\mathrm{m}^{2} / \mathrm{p}\right)$ and walking speed $(\mathrm{m} / \mathrm{min})$ exhibited in the Transit Capacity and Quality of Service Manual (Kittelson and Assoc 2013) and Fruin (1992).

$$
\begin{aligned}
& {\left[V_{\text {circ }}\right]_{1 \times 12}=\operatorname{Min}\left(\left(21.42 \times \ln \left[P S A_{\text {cell }}\right]_{1 \times 12}+78.17 \times[J]_{1 \times 12}\right),\right.} \\
& \left.\quad\left(21.42 \times \ln \left[P S A_{\text {cell }}\right]_{1 \times 12}+57.70 \times[J]_{1 \times 12}\right), 82\right)
\end{aligned}
$$

We then repeat the optimisations marked in Fig. 2 according to the system of Eqs. 7 to 48 using the calculated re-estimates of $\left[P S A_{\text {stry,cell }}\right]_{1 \times 12}$, and $\left[V_{\text {circ }}\right]_{1 \times 12}$ until the following objective functions are met:

$$
\begin{gathered}
\underset{\left[P S A_{\text {stry, cell }}\right]_{1 \times 12}}{\operatorname{argmin}}\left(\operatorname{abs}\left(\left[P S A_{\text {stry, cell }, n-1}\right]_{1 \times 12}-\left[P S A_{\text {strny,cell }, n}\right]_{1 \times 12}\right)\right) \\
\underset{\left[V_{\text {circ }}\right]_{1 \times 12}}{\operatorname{argmin}}\left(\operatorname{abs}\left(\left[V_{\text {circ }, n-1}\right]_{1 \times 12}-\left[V_{\text {circ }, n}\right]_{1 \times 12}\right)\right)
\end{gathered}
$$

where $P S A_{\text {stny,cell }, n-1}=$ stationary reference PSA in a cell from the previous iteration of the optimisation routine, $n-1$, or in the initial iteration is set to $P S A_{\text {stny, cell, init }}$. $P S A_{\text {stny,cell }, n}=$ stationary reference PSA in a cell from the current iteration of the optimisation routine, $n . V_{\text {circ }, n-1}=$ average passenger circulating speed through a cell from the previous iteration of the optimisation routine, $n-1$, or in the initial iteration is set to $V_{\text {circ,init }} . V_{\text {circ }, n}=$ average passenger circulating speed through cell from the current iteration of the optimisation routine, $n$.

Satisfaction of the Eqs. 49 and 50 results in the final system of matrices.

Existing QoS thresholds and service levels from the literature cannot be used to compare with overall PSA by a cell, as they have been developed considering one particular passenger activity only. Therefore, we develop threshold service levels on the basis of Fruin's QoS thresholds for stationary and circulating activities, respectively, by assigning $P M_{\text {stny }}$ and $P M_{\text {circ }}$ as weights, according to Eq. 51.

$$
\begin{aligned}
{\left[S L_{\text {cell }, F r, i}\right]_{1 \times 12}=} & \left(P S A_{\text {stny }, F r, i} \times\left[P M_{\text {stny }}\right]_{1 \times 12}+P S A_{\text {circ }, F r, i} \times\left[P M_{\text {circ }}\right]_{1 \times 12}\right) \\
& \varnothing\left(\left[P M_{\text {stny }}\right]_{1 \times 12}+\left[P M_{\text {circ }}\right]_{1 \times 12}\right)
\end{aligned}
$$

where $S L_{c e l l, F r, i}=$ threshold service level in cell, based on Fruin QoS weighted for stationary and circulating activities, $i \in(A, B, C, D, E, F)$.

Six service level thresholds are calculated for each cell uniquely because passenger-minutes taken for stationary and circulating activities are unique in each cell. These service level thresholds are specific to the study BRT platform 
conditions. However, this methodology may be applied in creating thresholds for other BRT platforms under their study conditions.

Using these thresholds, $P S A_{\text {cell }}$ values from Eq. 47 may be compared to appraise spatial comfort QoS and to ascertain variation in QoS between the platform's cells.

Next, we determine platform stationary reference PSA $\left(P S A_{\text {stny,plat }}\right)$ and platform circulating reference PSA ( $\left.P S A_{\text {circ,plat }}\right)$ using Eqs. 52 and 53, respectively.

$$
\begin{gathered}
P S A_{\text {stny }, \text { plat }}=\frac{\sum\left[T S_{\text {avail }}\right]_{1 \times 12}}{\sum\left[P M_{\text {stny }}\right]_{1 \times 12}+\frac{\sum\left[P M_{\text {circ }}\right]_{1 \times 12}}{0.384}} \\
P S A_{\text {circ }, \text { plat }}=\frac{P S A_{\text {stny }, \text { plat }}}{0.384}
\end{gathered}
$$

We determine platform overall PSA ( $\left.P S A_{\text {plat }}\right)$ using the sums of $P M_{\text {stny }}$ and $P M_{\text {circ }}$ across all cells of the platform as weights, according to Eq. 54.

$$
P S A_{\text {plat }}=\frac{\left(P S A_{\text {stny }, \text { plat }} \times \sum\left[P M_{\text {stny }}\right]_{1 \times 12}+P S A_{\text {circ }, \text { plat }} \times \sum\left[P M_{\text {circ }}\right]_{1 \times 12}\right)}{\sum\left[P M_{\text {stny }}\right]_{1 \times 12}+\sum\left[P M_{\text {circ }}\right]_{1 \times 12}}
$$

Similarly, we can apply service level thresholds to evaluate the platform considering both stationary and circulating passengers together according to Eq. 55 . This results in six threshold service levels ranging from $\mathrm{A}$ to $\mathrm{F}$.

$$
S L_{\text {plat }, F r, i}=\frac{\left(P S A_{\text {stny }, F r, i} \times \sum\left[P M_{\text {stny }}\right]_{1 \times 12}+P S A_{\text {circ }, F r, i} \times \sum\left[P M_{\text {circ }}\right]_{1 \times 12}\right)}{\sum\left[P M_{\text {stny }}\right]_{1 \times 12}+\sum\left[P M_{\text {circ }}\right]_{1 \times 12}}
$$

where $S L_{\text {plat }, F r, i}=$ platform overall threshold service level for Fruin QoS weighted for stationary and circulating activities, $i \in(A, B, C, D, E, F)$.

The value of $P S A_{\text {plat }}$ may be compared with the service level thresholds from Eq. 55, to appraise spatial comfort QoS of the platform overall.

\section{Assignment of variable utility weights to estimate the range in a passenger-specific area by cell}

It would be extremely difficult to develop a field data collection approach to precisely determine utility weights. We therefore select the factors' utility weights over a range of plausible values. We assume a set of utility weights such that $\left(W_{\text {Dist,ent }}+W_{\text {wait }, \text { PSA }}+W_{\text {Dist, } \text {,ntr }}+W_{\text {Dist }, \text { rear }}=1\right)$ in Eq. 32 . This results in a number of overall utility matrices equal to the number of combinations of utility weights considered. We apply the above methodology to each combination of utility weights separately. For each platform cell, this results in a pseudo-stochastic distribution of PSA across a range that is associated with the plausible range of utility weights. In the next section, we apply collected data from the study station to identify the most feasible values of the utility weights that can be used to replace initially assumed values. 


\section{Training and verifying the model}

We use data in Table 2 as input to train the model. We found it difficult to manually collect data about PSA because stationary and circulating passenger activities occur together. Due to ethical constraints imposed by the transit property, other data collection methods, such as video capture, were not feasible. Due to these two constraints, it was consequently necessary to develop means of verifying the trained model by comparing model outputs with collected data from which the expected (average) number of waiting passengers in platform cells at a given instant in time was calculated.

We average the cell-wise waiting passenger counts collected over the peak of the peak period and compare it with the resulting values of $P_{\text {wait,cell,ins }}$ from the model. Using this method, we identify the plausible range of utility weights for each utility factor as:

- Utility weight of the factor for the circulating distance from the entrance to the waiting cell, $W_{\text {Dist }, \text { ent }} \in\{0.65,0.70,0.75,0.80,0.85\}$.

- Utility weight of the factor for waiting PSA in the cells, $W_{\text {wait }, P S A} \in\{0.05,0.10\}$.

- Utility weight of the factor for the distance from the centre of the front strip to the waiting cell, $W_{\text {Dist }, \text { cntr }} \in\{0.05,0.10,0.15,0.20,0.25\}$.

- Utility weight of the factor for the distance from the centre of the waiting cell to the centre of the nearest rear strip cell, $W_{\text {Dist rear }} \in\{0.05,0.10\}$.

This results in 16 combinations of utility weights. During this stage of the study, where the real data are used to train the model, we determined that an exponent of two for the factor for the circulating distance from the entrance to the waiting cell $\left(D_{a v, t o t, c i r c, e n t}{ }^{2}\right)$, and an exponent of four for the factor for the distance from the centre of the front strip to the waiting cell $\left(D_{\text {front,cntr }}{ }^{4}\right)$ are required in the utility estimation section (Sect. 4.6). We argue that exponents in these two factors reflect the importance of passengers' perceptions of these two factors.

Applying the training data set in the model, the distribution of waiting passengers in each platform cell at a given instant in time is shown in Fig. 5 as a box and whisker plot. The data points in the figure are the verification data collected from the expected (average of the) waiting passenger count at a given instant in time. This verification data were collected on a Tuesday, a week later as the training data collection day, and re-scaled considering the total number of waiting passengers in platform cells at any given instant in time resulting from the model including the training data.

By inspection of Fig. 5, the expected waiting passenger count increases from the downstream end of the platform towards the upstream end. We postulate that this is due to passengers waiting close to the platform entrance, which is at the platform upstream end. However, there is a slight reduction in the count at cells 6 and 12, which we postulate is due to the obstruction of passengers' view of approaching buses by the guideway curvature just before the station and by the wall that separates the busway corridor from the platform entrance path. Further, passengers may avoid interaction with entering/exiting passengers, and passengers moving 
towards the platform centre due to the easy access to all loading areas and the availability of real-time bus arrival information screens at the platform centre.

By inspecting Fig. 5, we find that the number of waiting passengers in rear strip cells is always higher than the number of waiting passengers in their adjacent front strip cells. We postulate that this is due to the availability of platform amenities at the rear side of the platform along with less obstruction from dwelling process (boarding and alighting).

By comparing the model average in each cell with the verification data in Fig. 5, we can observe that verification data lie within or near the range of values resulting from the model. Both sets exhibit a similar pattern. The correlation between the average of the distribution of the expected number of waiting passengers estimated using the model with the training data and the verification data collected from the expected (average of the) waiting passenger count at a given instant in time, across the 12 cells was compared by performing a linear regression analysis in the Statistical Package for the Social Sciences (SPSS). The correlation was found to be strong with an r-value of 0.988 and a p-value of 0.000 . That indicates the distribution of the expected number of waiting passengers estimated using the model with the training data and the verification data collected from the expected (average of the) waiting passenger count at a given instant in time are strongly correlated in direction and strength. These results verify the model.

\section{Testing the model}

To test the applicability of the model, we used data collected at the same study station on a different weekday (Thursday), during the evening 15-min peak of the peak period $(3.30 \mathrm{pm}-3.45 \mathrm{pm})$. Table 3 indicates the input data while Fig. 6 denotes the distribution of the expected number of waiting passengers in cells at a given instant in time estimated from the model along with verification data collected from the expected (average of the) waiting passenger count at a given instant in time for this day of the following week. These verification data were also re-scaled using the total number of waiting passengers in the platform cells at any given instant in time resulting from the model including the testing data.

In Fig. 6, the same variation can be observed as for the training data set in Fig. 5. When performing linear regression analysis in SPSS, correlation was found to be strong with an r-value of 0.996 and a p-value of 0.000 . This indicates that the distribution of the expected number of waiting passengers in the cells at a given instant in time estimated from the model with the testing data and the verification data collected from the expected (average of the) waiting passenger count at a given instant are strongly associated with one another. These results again verify the model.

By training and testing the developed model using real data, we verify the applicability of this model to BRT station platforms. The following section indicates the PSA and service levels resulting from the model. 


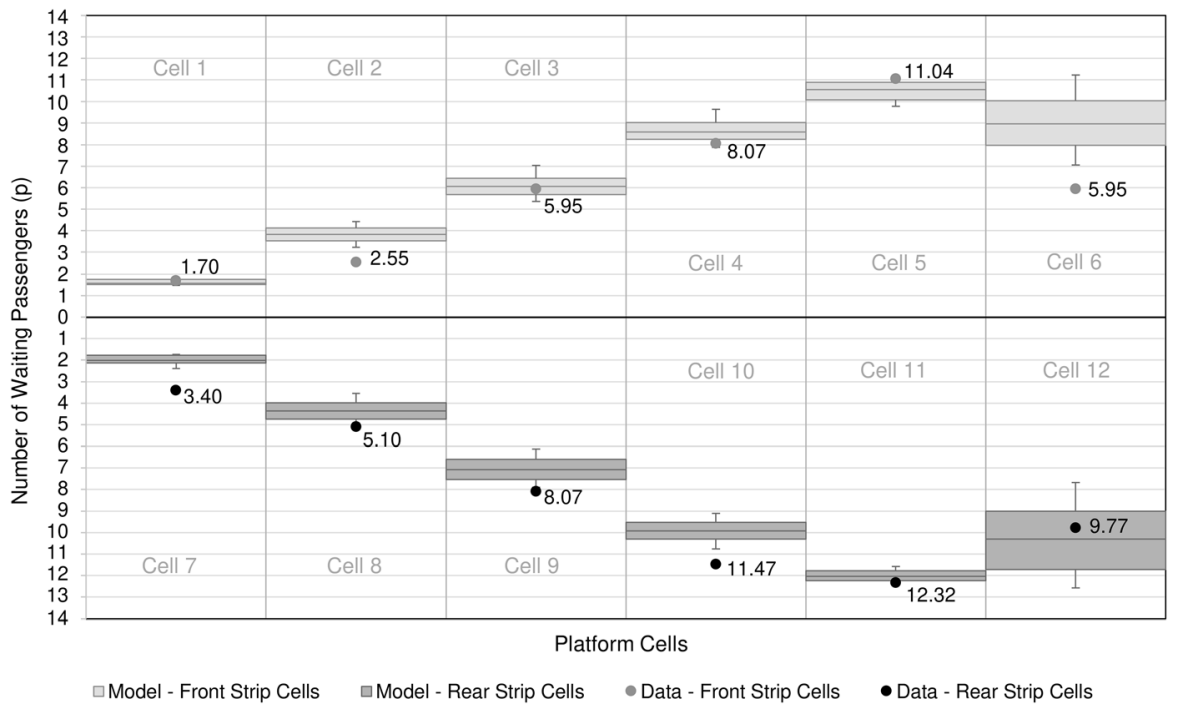

Fig. 5 Waiting passenger distribution in Mater Hill Busway Station, outbound platform - training model output vs verification data, peak of the peak period, Tuesday, $3.30 \mathrm{pm}-3.45 \mathrm{pm}$

\section{Results}

Table 4 reports the resulting PSA and service levels for each QoS in each cell, and across the platform, with the model calibrated using the training and testing data, respectively. These outputs represent the averages of values across the 16 combinations of utility weights. The position of each value in the $[2$ row $\times 6$ column] matrices reflects the physical cell position on the platform. For easy display, the [1 row $\times 12$ column] matrices representing platform cells are dropped down by a line for columns 7 to 12 .

\section{Discussion}

The methodology developed in this study facilitates the quantitative evaluation of PSA on a cell by cell basis and across the whole BRT platform, and appraisal of spatial comfort using Fruin's QoS criteria (Fruin 1992). The model developed with data for the peak of the peak periods of the training day on Tuesday and the testing day on Thursday at the study platform, is strongly correlated with the verification data at a correlation ( $r$-value) of 0.988 and 0.996 , respectively. When considering the results that were determined using the model for training and testing data at the study platform, the overall PSA by cell gradually increases from the downstream end of the platform (left side of Fig. 3), which is the farthest from the entrance/exit location, towards the upstream end of the platform, which is close to the platform entrance/exit. The lowest PSA is observed at cell 5 and cell 11. We postulate the reasons for this as being the same reasons indicated in Sect. 6, for the waiting passenger distribution. When comparing stationary reference PSA with circulating 
Table 3 Model testing-input data

\begin{tabular}{lcc}
\hline Item & Value & Units \\
\hline $\begin{array}{l}\text { Peak of the peak duration } \\
\text { Evaluation period }\end{array}$ & 15 min \\
& $\begin{array}{c}\text { Evening peak of the } \\
\text { peak period } \\
\text { (3.30 pm-3.45 pm) }\end{array}$ \\
Number of buses servicing at each loading area during the evaluation period (Different bus routes)
\end{tabular}

reference PSA in the cells, the values resulting for the same platform cell differed significantly. That indicates the importance of considering both stationary and circulating activities when evaluating platform PSA.

The cell-wise PSA from the model that was calibrated using the testing data, which was collected on Thursday, shows higher values when compared with the training data, which was collected on Tuesday. The reason for this difference are the lower passenger waiting times in the testing data set. This difference in PSA resulted in overall cell-wise QoS in the testing data set resulting in QoS B only at cells 5 and 11, while for the training data set, QoS resulted in B and C in the upstream half of the platform. However, both cases resulted in the cells in the downstream half of the platform operating at QoS A. We postulate the reason for the reduced QoS in the upstream side of the platform as being the passengers waiting near the platform entrance at the upstream end. Further, in the model calibrated using the training data set, QoS C in cell 11 may have resulted from the attraction of that cell being a rear strip cell as well as being close to the platform entrance.

The study station is highly congested during a 30-min period prior to each data collection period, due to the release of students from several adjacent high schools. However, due to the difficulty in manually collecting data during this period, and for privacy reasons imposed by the transit property, we instead observed a peak of the peak commuter period in the afternoon immediately after the school peak period. We anticipate inferior QoS during the school peak period.

When considering the stationary, circulating and overall PSA for the whole platform, the model that was calibrated using testing data resulted in higher values than the model calibrated using training data. We postulate the reasons for this difference to be the same as discussed above. However, the overall platform PSA resulted in QoS A for both cases. Although most of the cells of the platform were operating at QoS A, some operated at QoS B, while some operated at QoS C. 


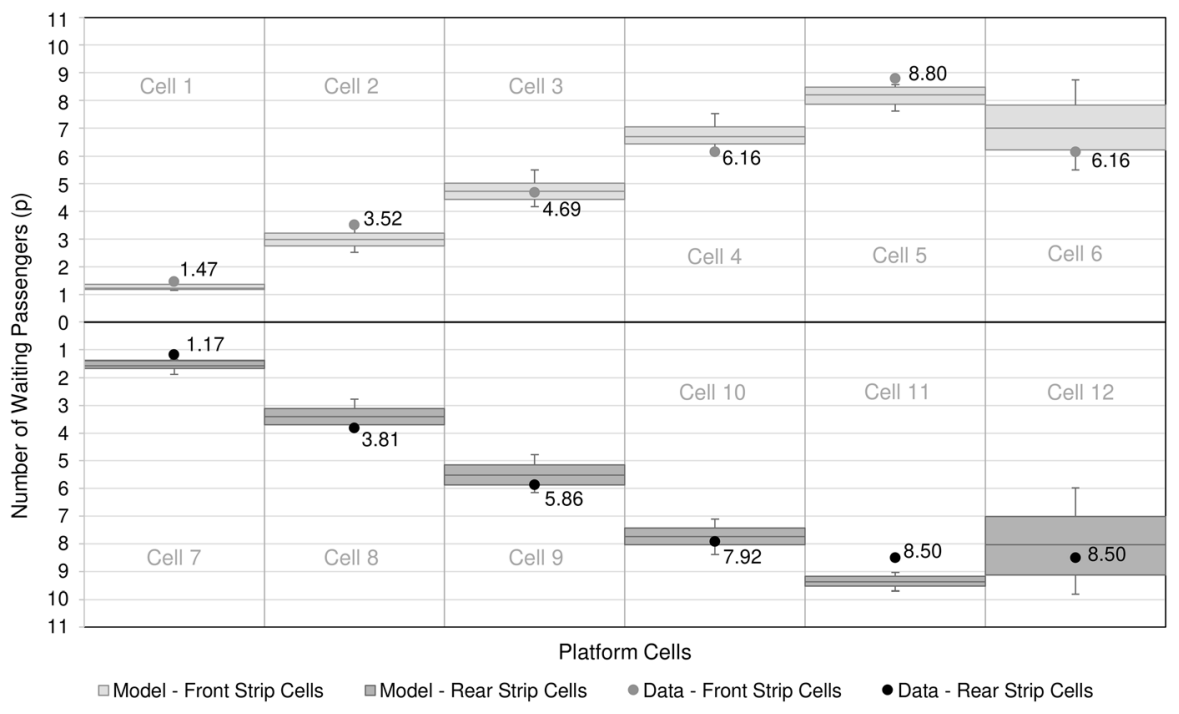

Fig. 6 Waiting passenger distribution in Mater Hill Busway Station, outbound platform-testing model output vs. verification data, Peak of the Peak Period, Thursday, 3.30 pm-3.45 pm

Therefore, evaluating the whole platform as a single area only may underestimate and/or overestimate the performance of some locations of the platform. That demonstrates the importance of evaluating the PSA and hence QoS on a cell-by-cell basis, which is helpful in identifying locations with poor operation and to consider improvement measures. As the case study platform has only one effective entrance/ exit, we consider that these QoS values are acceptable; however, it is prudent to employ crowd management, should conditions reach QoS D or E, as we anticipated during the school peak period.

By understanding the critical cells on the platform with high passenger crowds, measures can be implemented to distribute passengers more evenly across the platform, which may even out QoS throughout the platform space. This will improve passenger comfort as well as platform operation.

Examples of how this methodology can help practitioners in BRT platform operation management include:

- A better understanding of how passengers use the platform and how to direct passengers across the platform.

- In design of BRT platforms, the ability to evaluate treatments to better distribute passengers throughout the platform in order to achieve more even PSA throughout the platform. Treatments may include entrance/ exit locations, signage and guidance to passengers on waiting locations, improved real-time information display, public address, smart device application information/ advice, relocation of platform furniture, and so on. 


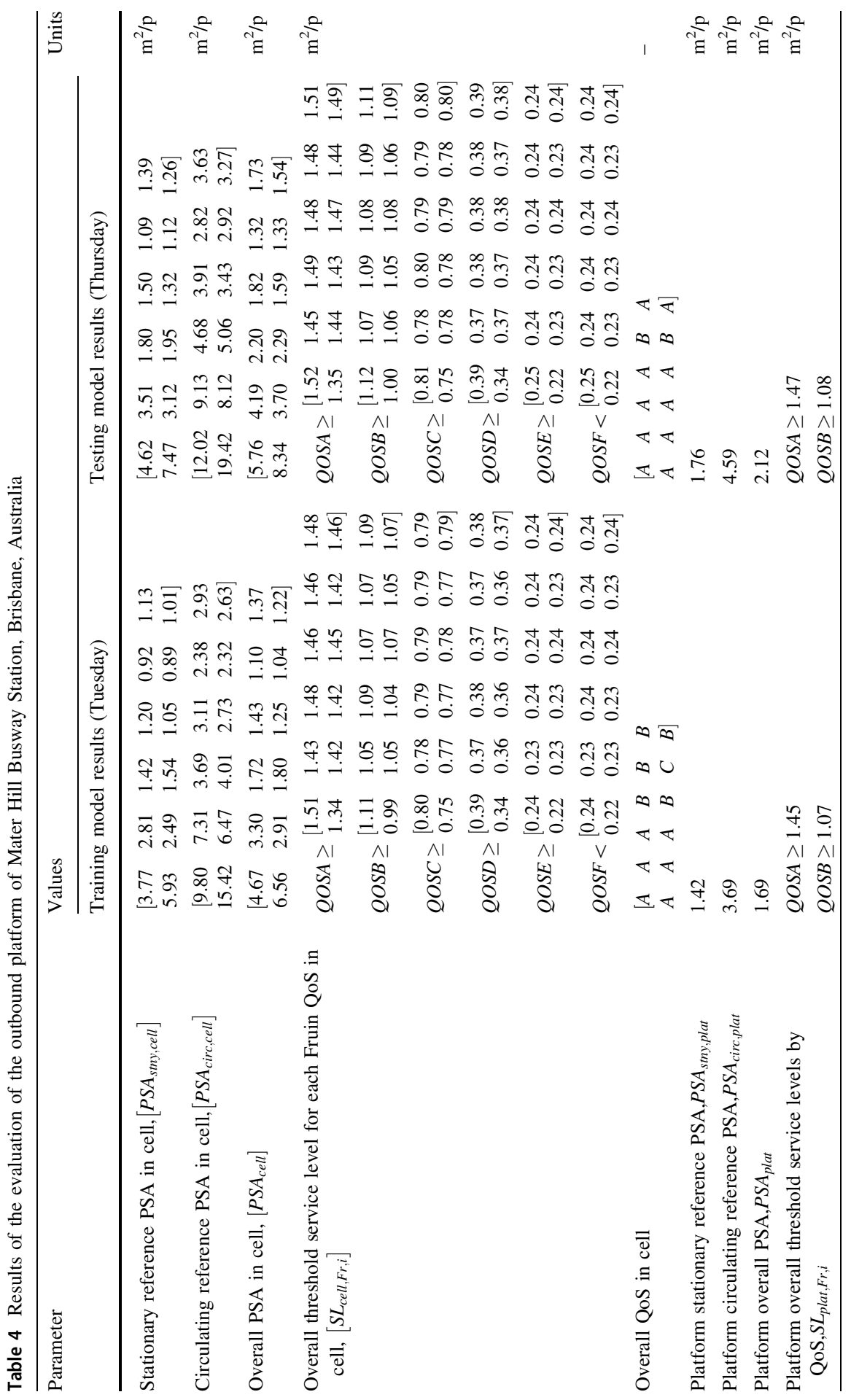




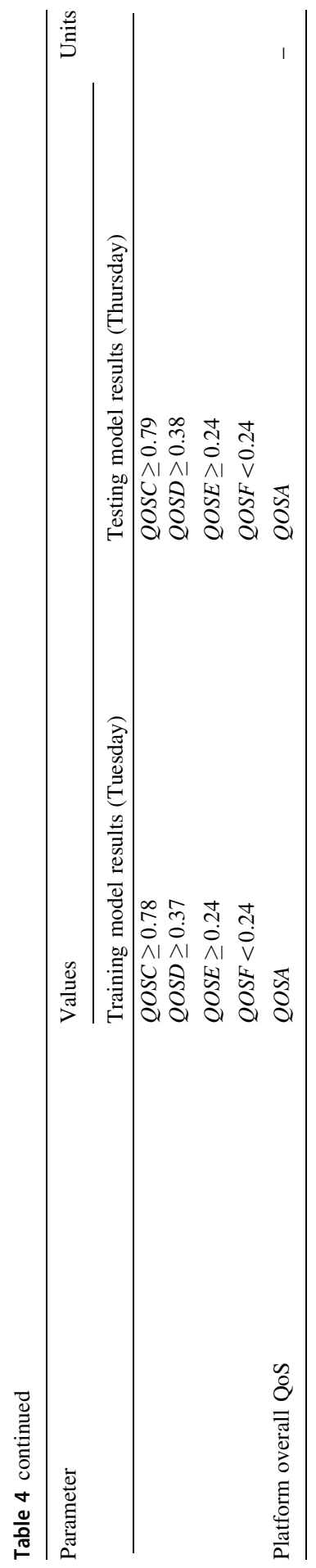

\section{Springer}




\section{Conclusions and further research}

The evaluation of bus rapid transit (BRT) station platform performance in terms of passenger-specific area (PSA) is key to assess how passengers perceive the spatial comfort quality of service. For the evaluation of transit station platforms, in which different passenger activities take place on a common space, the Transit Capacity and Quality of Service Manual (Kittelson and Assoc 2013) suggests the use of pedestrian microscopic simulation software or the use of a time-space analysis. But a methodology for evaluation of the overall PSA of BRT platforms, by combining different passenger activities, is not available in the current literature. Some researchers have highlighted the importance of evaluating PSA of stationary and circulating areas of transit platforms separately (Hänseler et al. 2016; Wu and Ma 2013). But they did not focus on BRT station platforms or consider partitioning the platform space into cells. Considering these gaps, a methodology was developed in this study to combine different passenger activities on a BRT station platform and quantitatively evaluate the overall PSA of each cell and of the whole platform.

Quality of service (QoS) thresholds defined by Fruin (1992) for queuing (stationary) and walking (circulating) areas were combined. The resultant overall threshold service levels by QoS were used to determine overall QoS variation throughout the BRT station platform.

While this methodology is only thought for BRT station platforms, it can be adapted to any station layouts and characteristics under their study conditions.

Forthcoming stages of this study will focus on developing generalised service level thresholds for BRT station platforms considering stationary activities and circulating activities together. The effect of interchanging passengers, and several entrance/exit locations at the platform, on PSA will be evaluated during the following stages of this study. Furthermore, the impact of COVID-19 on waiting passenger distribution on BRT station platforms is evaluated through further research.

Acknowledgements The authors acknowledge the TransLink division of the Department of Transport and Main Roads, Queensland, Australia for granting permission to access busway stations for manual data collection and observation of operation.

Author contributions The authors confirm contribution to the paper as follows: study conception and design: SJ and JMB with review by $\mathrm{AB}$; data collection: SJ with review by JMB; analysis and interpretation of results: SJ and JMB with review by $\mathrm{AB}$ and $\mathrm{MM}$; draft manuscript preparation: SJ and JMB with review by $\mathrm{AB}$ and $\mathrm{MM}$. All authors reviewed the results and approved the final version of the manuscript.

Funding The researcher has a Postgraduate Research Award scholarship from the Queensland University of Technology, Australia. There is no other funding source for the project.

Data availability The authors declare that data can be made available on request.

\section{Compliance with ethical standards}

Conflict of interest The authors declare that there are no conflicts of interest. 
Ethical approval Ethics approval for the research has been granted by the Human Research Ethics Committee of the Queensland University of Technology, Australia. During this stage of the study, data were collected through manual observation of operation of the study platform and therefore, informed consent was not required.

\section{References}

Benz GP (1986) Application of the time-space concept to a transportation terminal waiting and circulation area. Transp Res Rec J Transp Res Board 1054:16-22. https://trid.trb.org/view/277272

Bosina E, Britschgi S, Meeder M, Weidmann U (2015) Distribution of passengers on railway platforms. 15th swiss transport research conference (STRC 2015)

Bunker JM (2018) High volume bus stop upstream average waiting time for working capacity and quality of service. Publ Trans 10(2):311-333. https://doi.org/10.1007/s12469-018-0179-1

Duduta N, Subedi A (2015) Understanding platform overcrowding at bus rapid transit stations. Transp Res Rec J Transp Res Board 2533:118-123. https://doi.org/10.3141/2533-13

Elhamshary M, Youssef M, Uchiyama A, Yamaguchi H, Higashino T (2016) TransitLabel: A crowdsensing system for automatic labeling of transit stations semantics. Proceedings of the 14th annual international conference on mobile systems, applications, and services. pp 193-206. https://doi.org/ $10.1145 / 2906388.2906395$

Evans GW, Wener RE (2007) Crowding and personal space invasion on the train: please don't make me sit in the middle. J Environ Psychol 27:90-94. https://doi.org/10.1016/j.jenvp.2006.10.002

Fan W, Machemehl RB (2002) Characterizing bus transit passenger waiting times. 2nd material specialty conference of the Canadian society for civil engineering 1:1-10

Fletcher G, El-Geneidy A (2013) Effects of fare payment types and crowding on dwell time. Transp Res Rec J Transp Res Board 2351:124-132. https://doi.org/10.3141/2351-14

Fruin J (1971) Designing for pedestrians: a level-of-service concept. Highway research record, number 355: pedestrians, highway research board, Washington DC:1-15. https://trid.trb.org/view/116491

Fruin J (1992) Designing for pedestrians. Gray G, Hoel L (Eds.). Public transportation in the United States. Prentice Hall, Englewood Cliffs. pp 188-204

Grigoriadou M, Braaksma JP (1986) Application of the time-space concept in analyzing metro station platforms. ITE J 56(5):33-37

Hänseler FS, Bierlaire M, Scarinci R (2016) Assessing the usage and level-of-service of pedestrian facilities in train stations: a Swiss case study. Transp Res Part A Policy Pract 89:106-123. https:// doi.org/10.1016/j.tra.2016.05.010

Hermant L, De Gersigny M (2010) Microscopic assessment of pedestrian space requirements within railway stations in South Africa. 29th Southern African transport conference (SATC 2010), pp 290-300. http://hdl.handle.net/2263/14849

Hinebaugh D (2009) Characteristics of bus rapid transit for decision-making. United States Department of Transportation, Project No. FTA-FL-26-7109.2009.1. https://rid.trb.org/view/889597

Hridya V, Geeva G (2018) Quantitative evaluation of bus terminal using time-space analysis. Proceedings of the international conference in emerging trends in engineering, science and technology (ICETEST), January 18-20, 2018, Thrissur, Kerala, India. CRC Press, pp 179-184

Islam MR, Hadiuzzaman M, Banik R, Hasnat MM, Musabbir SR, Hossain S (2016) Bus service quality prediction and attribute ranking: a neural network approach. Publ Transp 8(2):295-313. https://doi. org/10.1007/s12469-016-0124-0

Jaiswal S (2010) Busway platform bus capacity analysis. Dissertation, Queensland University of Technology

Jaiswal S, Bunker J, Ferreira L (2008) Relating bus dwell time and platform crowding at a Busway station. 31st Australasian transport research forum (ATRF), pp 239-249. https://eprints.qut.edu.au/ $15023 /$

Jaiswal S, Bunker J, Ferreira L (2010) Influence of platform walking on BRT station bus dwell time estimation: Australian analysis. J Transp Eng 136:1173-1179. https://doi.org/10.1061/(ASCE)TE. $1943-5436.0000174$

Jayatilake S, Bunker J (2021) Impact of COVID-19 on waiting passenger distribution on a bus rapid transit station platform [in-press]. 100th Annual Meeting of the Transportation Research Board, Washington, D.C 
Jayatilake S, Bunker J, Bhaskar A, Miska M (2020) Passenger specific area on bus rapid transit station platforms [Poster presentation]. 99th Annual meeting of the transportation research board, Washington, D.C. https://eprints.qut.edu.au/136850/

Kittelson \& Assoc I, Parsons Brinckerhoff, Inc., KFH Group, Inc., Texas A\&M Transportation Institute, Arup (2013) Transit capacity and quality of service manual. Third edition. Transportation Research Board of the National Academies, Washington D.C

Krstanoski N (2014) Modelling passenger distribution on metro station platform. Int J Traffic Transp Eng 4(4):456-465. https://doi.org/10.7708/ijtte.2014.4(4).08

Lam WHK, Cheung C-Y, Lam CF (1999) A study of crowding effects at the Hong Kong light rail transit stations. Transp Res Part A Policy Pract 33:401-415. https://doi.org/10.1016/S09658564(98)00050-0

Lee JY, Lam WH, Wong S (2001) Pedestrian simulation model for Hong Kong underground stations. Intelligent transportation systems conference proceedings (IEEE), pp 554-558. https://doi.org/10. 1109/ITSC.2001.948719

Li F, Duan Z, Yang D (2012) Dwell time estimation models for bus rapid transit stations. J Mod Transp 20:168-177. https://doi.org/10.1007/BF03325795

Miskeen MAAB, Alhodairi AM, Rahmat RAABO (2013) Modeling a multinomial logit model of intercity travel mode choice behavior for all trips in Libya. Int J Civ Environ Eng 7:636-645. https:// doi.org/10.5281/zenodo.1087592

Muraleetharan T, Hagiwara T (2007) Overall level of service of urban walking environment and its influence on pedestrian route choice behavior: analysis of pedestrian travel in Sapporo, Japan. Transp Res Rec J Transp Res Board 2002:7-17. https://doi.org/10.3141/2002-02

Seriani S, Fujiyama T, Holloway C (2017) Exploring the pedestrian level of interaction on platform conflict areas at metro stations by real-scale laboratory experiments. Transp Plan Technol 40:100-118. https://doi.org/10.1080/03081060.2016.1238574

Teng J, Pan W, Zhang C (2020) Quantitative modeling of congestion in metro station based on passenger time perceptions. Transp Res Rec J Transp Res Board 2674(5):270-281. https://doi.org/10.1177/ 0361198120914900

Voß S, Mejia G, Voß A (2020) Mystery shopping in public transport: the case of bus station design. In: Stephanidis C, Marcus A, Rosenzweig E, Rau PLP, Moallem A, Rauterberg M (Eds.). HCI International 2020-late breaking papers: user experience design and case studies. HCII 2020. Lecture notes in computer science. Springer, Cham. 12423:527-542. https://doi.org/10.1007/978-3030-60114-0_36

Wiggenraad PB (2001) Alighting and boarding times of passengers at Dutch railway stations-analysis of data collected at 7 railway stations in October 2000. TRAIL Research School, Delft

Wu J, Ma S (2013) Division method for waiting areas on island platforms at metro stations. J Transp Eng 139:339-349. https://doi.org/10.1061/(ASCE)TE.1943-5436.0000484

Yang B, Yan X, Guo D (2015) Level of service analysis based on maximum number of passengers in waiting room of railway passenger station using arena simulation. Discret Dyn Nat Soc. https://doi. org/10.1155/2015/452035

Publisher's Note Springer Nature remains neutral with regard to jurisdictional claims in published maps and institutional affiliations. 